\title{
Lessons Learned from a \\ Global History \\ of Pandemics
}

\author{
Lenos Archer-Diaby \\ Editorial Assistant
}

Citation: EMJ Microbiol Infect Dis. 2020;1[1]:38-41.

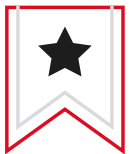

D ANDEMIC: the term making headlines across the world, instilling fear in many, and urging scientists across the world to unite and find a cure. For as long as the global population has exploited freedom of travel, so too have infectious diseases spread. Outbreaks have been nearly constant since the dawn of mankind; however, not all escalate to global levels. There have been many pandemics in history, the most recent being COVID-19 declared as such by the World Health Organization (WHO) on March 12 ${ }^{\text {th }}, 2020 .{ }^{1}$ As the COVID-19 pandemic continues to disrupt our everyday lives, it is important to look back in history and reflect on what previous pandemics have taught us.
\end{abstract}

\section{EPIDEMIOLOGY}

Throughout the course of history, neither wars or natural disasters have killed as many humans as the viruses, bacteria, and parasites that cause disease. $^{2}$ Within our environment, a myriad of infectious pathogens perpetually surrounds us, some leading to mild or severe symptoms and others leading to none at all. The risk of infection is dependent on health, immunity, and in some cases even luck. When one of these diseases rapidly infects thousands within a community, population, or region, it is classified as an epidemic. When an epidemic spreads across multiple countries or continents it is referred to as a pandemic, a severe and worst-case scenario demanding immediate action. ${ }^{3}$

The introduction of agrarian communities led to an increased scale and spread of diseases. Widespread trade routes created new opportunities for zoonosis aiding the spread of epidemics such as malaria, influenza, and smallpox, all of which first appeared during this time. ${ }^{4}$ As time progressed and humans settled in larger cities, established long-distance trade routes, and increased contact with various populations of people, animals, and ecosystems, ${ }^{4}$ the likelihood of pandemics increased.

\section{YERSINIA PESTIS: THE FIRST PLAGUE}

A pinpoint in the history of pandemics is the first recorded outbreak of the plague, the plague of Justinian (541-542 AD, with recurrences until 750 $A D)$, which was carried over the Mediterranean Sea from Egypt to Constantinople. Fleas carrying the bacteria Yersinia pestis infected rats, and these plague-infected rodents travelled aboard grain ships heading towards Constantinople. The rats thrived in the granaries, breeding rapidly and amplifying the contagion. This spread among the human population, and quickly dispersed across Europe, Asia, and North Africa, claiming the lives of an estimated $30-50$ million people. ${ }^{3}$ During this time, there was no understanding of the origin of 
the plague and how to fight it other than to avoid those who were sick. Many ancient societies believed that spirits and gods inflicted disease and destruction upon those that deserved their wrath. ${ }^{4}$ Even though the understanding of the pandemic at the time was limited, and factors such as poor sanitation and hygiene facilitated its spread, parallels can still be drawn to the COVID-19 pandemic as both originated from animal to human transmission. The fact that despite the above drawbacks humanity managed to overcome the plague, amid an enormous death toll, indicates the resilience of the human race, which could be an ally in overcoming COVID-19.

\section{THE BLACK DEATH: QUARANTINE AS A MEANS TO PREVENT SPREAD}

How the plague ended is yet to be defined, yet the consensus is that those that survive a pandemic have immunity. ${ }^{3}$ Unfortunately, the first plaque never disappeared and returned 800 years later. During these years we learnt to travel further and faster; built more populous cities; and armies, colonisers, and traders all imported and exported the disease on ships and land, ${ }^{5}$ all of which allowed far easier transmission of pathogens than during the previous plague. In just 4 years the Black Death was responsible for the death of one-third of the world population (200 million). There was still no understanding of how to stop the disease; however, it was understood that the spread of the disease was related to proximity. ${ }^{3}$ Soon after the plague arrived in Europe, emergency public health measures were invoked that foreshadow today's best practices of social distancing. ${ }^{6}$ The word quarantine stems from the Venetian word quarantena (40 days) referring to the 40 days ships were required to wait in the harbour before docking to ensure that no one aboard was carrying the plague. 


\section{UNDERSTANDING THE SCIENCE: THE FIRST VACCINE}

The efforts to tackle COVID-19 have primarily focussed on producing a vaccine against SARSCoV-2. In what currently sounds like a best-case scenario, the ultimate goal would be to produce a vaccine that completely eradicates COVID-19, much like the smallpox vaccine led to the ultimate eradication of smallpox. For centuries, smallpox, caused by the virus Variola major or Variola minor, was endemic to Europe and Asia. Yet, the death rate paled in comparison to the devastation it brought to native populations when the virus arrived in the New World in the $15^{\text {th }}$ century with the first European explorers. ${ }^{7}$ Unfortunately, the indigenous population had no innate or acquired immunity to smallpox, and from 1520 onwards the disease has killed 56 million. However, as time had passed so had humanity's scientific understanding of pathogens grown. In many cases we have learnt from previous outbreaks to develop new techniques in treatment and prevention, such as the case for smallpox. In the $18^{\text {th }}$ century, Edward Jenner discovered that those inoculated with a milder virus (cowpox) appeared immune to smallpox and thus smallpox became the first pandemic to be ended by a vaccine. ${ }^{7}$

Whether this will be the case for COVID-19 is something that remains to be determined.

\section{AIRBORNE: PATHOGENS TAKING FLIGHT}

Just as World War I was coming to an end, the world was struck by another pandemic in the form of Spanish flu (H1N1 [1918-1920]). The virus was airborne and spread through the sneezes and coughs of those infected. Unbeknownst to them, World War I troops that had worked in close quarters and then travelled around the world allowed the deadly influenza to spread rapidly. In 2 years, 40-50 million deaths were attributed to the virus. ${ }^{3}$ Social isolation measures were invoked in many communities, including cancelling public events and closing schools, significantly reducing the spread of the disease. While most infectious diseases are particularly dangerous to the elderly, the very young, and those that are already immunocompromised, the Spanish flu bucked this trend by affecting the healthy and young to a similar degree. Although the jury is still out on whether COVID-19 is an airborne disease, ${ }^{8}$ social distancing is the widely accepted course of action for slowing down its spread. However, unlike the Spanish flu, in the case of COVID-19 age seems to be a key determining factor of mortality, in addition to other less wellunderstood factors such as obesity. ${ }^{9}$

\section{MODERN PROBLEMS: MISCONCEPTIONS AND DISEASE PREVENTION}

Since the last pandemic, we have taken massive leaps forward in improved sanitation, hygiene, and nutrition, making the human population healthier and less vulnerable to illness than ever before. Despite this, we continue to face challenges. HIV is considered a pandemic by some; however, the WHO currently uses the term 'global epidemic.' To this day 35 million people worldwide have died of the disease and a cure is yet to be found. ${ }^{3}$ These numbers are attributable to the spread of misinformation, especially amplified by homophobic attitudes in light of inaccurate scientific information during the initial outbreak in the 1980s. Prevention methods failed to reach people both within and beyond the targeted population as the public considered AIDS a disease of men who have sex with men. It was not until society acknowledged that AIDS can affect everyone that prevention increased and infection declined. This reinforces the view that dissemination of accurate information to the public, alongside medical progress is key in curbing a pandemic.

\section{CONCLUSION}

Despite the persistence of disease and pandemics throughout history, humanity has always continued to move forward and the gradual reduction in the death rate has been a consistent trend. Understanding the factors that nurture pandemics and improvements in healthcare have been powerful tools in mitigating their impact. It has been many years since humanity discerned the origin of these pandemics as being rooted in infectious microbes, as opposed to vengeful deities. This realisation foreshadowed continual learning and adaptation in the face 


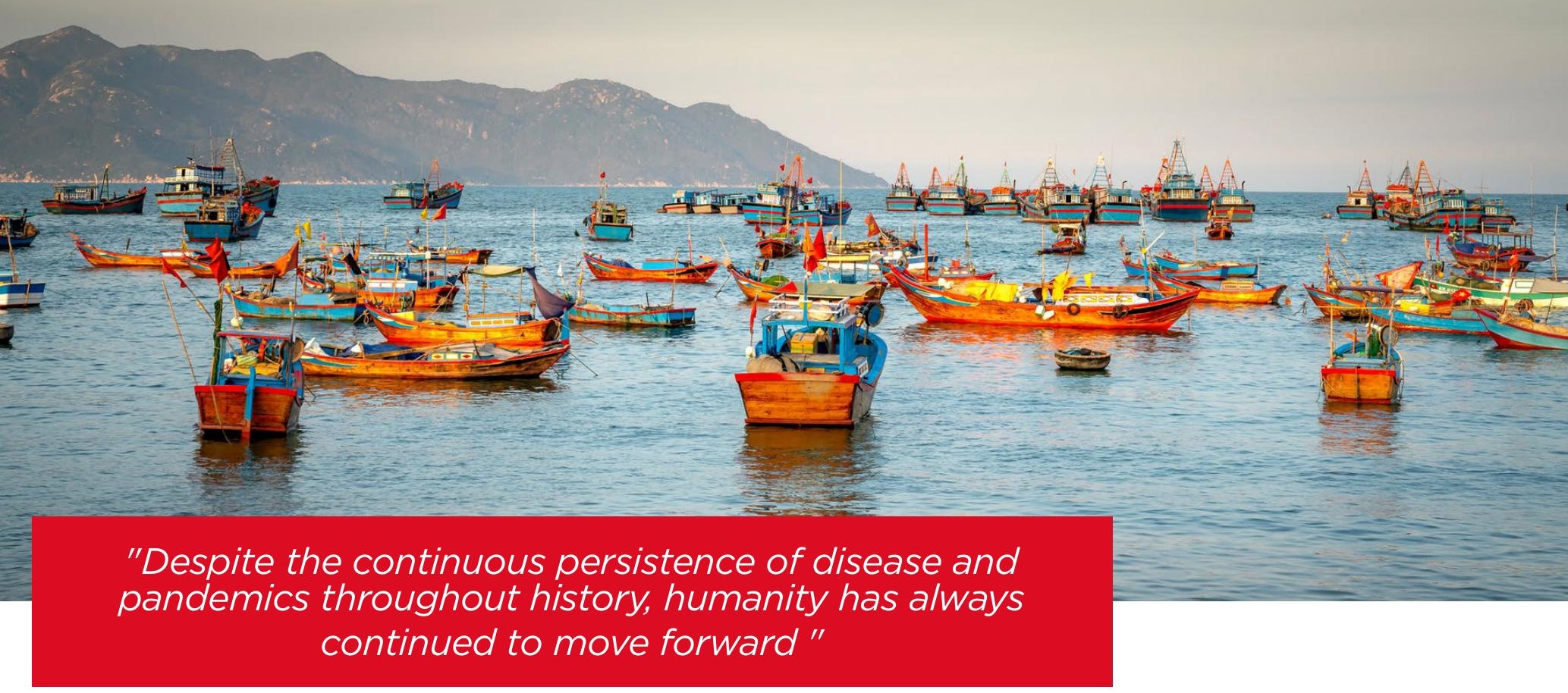

of countless challenges. This adaptation has included quarantining the infected, enacting social distancing measures, and conducting geographical and statistical analysis in order to limit the spread, alongside the discovery of vaccines. Pandemics are more likely to occur if the threat has not been seen before and is easily transmissible, as is the case for COVID-19. However, the measures introduced by governments have enabled the pandemic to be better contained than those previously. The modern generation is experiencing the challenges of a pandemic first-hand and learning the importance of strict social distancing and prevention measures. Contact tracing, personal protective equipment, and testing have proven pivotal in the face of all pandemics. By implementing preparations for these events far earlier in the process, pandemics can be ended more quickly and met with better success, limiting disruption to life.

\section{References}

1. World Health Organization (WHO) Europe. 2020 Available at: http://www.euro.who.int/en/health-topics/ health-emergencies/coronavirus-covid-19/news/ news/2020/3/who-announces-covid-19-outbreak-apandemic. Last accessed: 29 April 2020.

2. BBC Future. 2020. Available at: https://www.bbc.com/ future/article/20200325-covid-19-the-history-ofpandemics. Last accessed: 30 April 2020.

3. History. 2020. Available at: https://www.history.com/ topics/middle-ages/pandemics-timeline. Last accessed: 30 April 2020

4. Visual Capitalist. 2020. Available at: https://www. visualcapitalist.com/history-of-pandemics-deadliest/. Last accessed: 30 April 2020

5. Science Museum. 2019. https://www.sciencemuseum.org uk/objects-and-stories/medicine/bubonic-plague-firstpandemic. Last accessed: 30 April 2020.

6. History. 2020. Available at: https://www.history.com/ news/quarantine-black-death-medieval. Last accessed: 30 April 2020.

7. History. 2020. Available at: https://www.history.com/ news/pandemics-end-plague-cholera-black-deathsmallpox. Last accessed: 30 April 2020.

8. Nature. Is the coronavirus airborne? Experts can't agree. 2020. Available at: https://www.nature.com/articles/ d41586-020-00974-w. Last accessed: 27.05.2020.

9. Giacomelli A et al. 30-day mortality in patients hospitalized with COVID-19 during the first wave of the Italian epidemic: a prospective cohort study. Pharmacological Research. 2020; 104931. https://doi. org/10.1016/j.phrs.2020.104931. 